\title{
Resenha
}

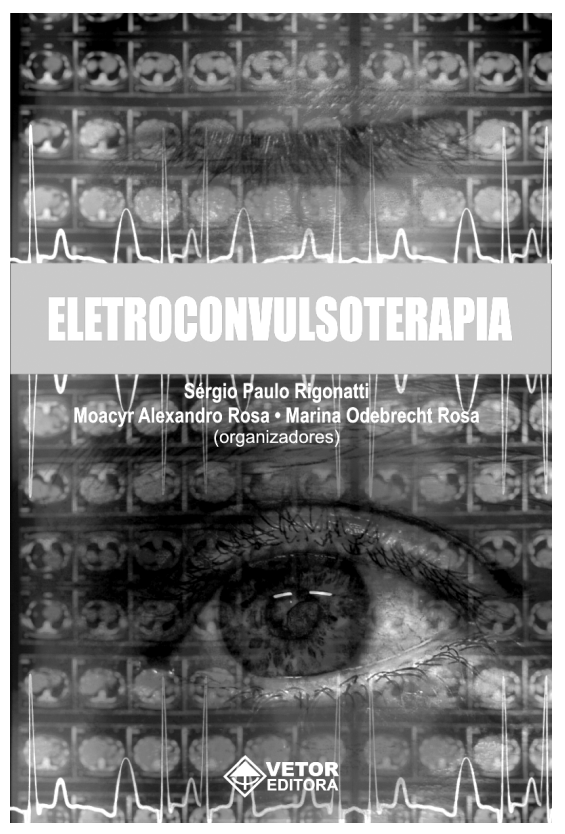

Após conhecer pessoalmente o Prof. Dr. Sérgio Rigonatti, no lançamento deste livro, e tê-lo lido duas vezes, tive a ousadia de fazer esta resenha.

O livro conta com mais dois organizadores além do Prof. Rigonatti - Dra. Marina O. Rosa e Dr. Moacyr A. Rosa - e 19 colaboradores, formando uma exímia equipe multidisciplinar. $O$ prefaciante é o Prof. Dr. Carol Sonenreich, e a apresentação é do pujante Prof. Dr. Marco Antonio Brasil.

O livro tem uma linguagem objetiva, lógica e clara, de fácil compreensão até mesmo para os leigos no assunto, o que, para um tema tão estigmatizado, já é um grande mérito.

No Capítulo I, cronologicamente, é apresentada a história dos tratamentos psiquiátricos mais conhecidos, sendo que a eletroconvulsoterapia (ECT) foi o primeiro com eficácia comprovada entre os tratamentos biológicos ao longo da história. $\mathrm{Na}$ atualidade, a ECT é realizada em larga escala em muitos países, inclusive no Brasil - provavelmente mais

* Rigonatti SP, Rosa MA, Rosa MO, orgs. Eletroconvulsoterapia. São Paulo: Vetor; 2004. $163 \mathrm{p}$.

**Psiquiatra, Doutor em Saúde Mental (Unicamp), Pós-Doutor e Professor da Faculdade de Medicina de Lisboa, Professor da Universidade Católica

\section{Resenha do livro Eletroconvulsoterapia, de Sérgio Paulo Rigonatti, Moacyr Alexandro Rosa e Marina Odebrecht Rosa (orgs.)*}

\author{
José Carlos Souza**
}

em clínicas privadas do que públicas.

No segundo capítulo, didaticamente, os autores discutem o mecanismo de ação da ECT, que, "embora não seja ainda completamente conhecido, há teorias importantes relacionadas ao assunto, sendo as três principais: a teoria clássica dos neurotransmissores, a neuroendócrina e a anticonvulsiva. Esta última afirma que o efeito antidepressivo da ECT está relacionado ao fato do seu profundo efeito anticonvulsivante no cérebro".

No terceiro capítulo, os autores desmistificam a técnica da ECT, tão desconhecida por muitos profissionais de saúde de áreas afins à psiquiatria e pelo público em geral. Discutem os prós e contras de cada técnica e enfatizam a necessidade de ligação da psiquiatria com as outras especialidades médicas, especialmente a cardiologia.

No quarto capítulo, o Prof. Rigonatti e três colaboradores (o Dr. Demétrio Rumi, o pósgraduando em Cardiologia Júlio Takada e a Dra. Maria Solimene) apresentam as indicações e contra-indicações da ECT. Cabe aqui ressaltar que alguns estudos mundiais discutem de maneira mais branda e menos complexa do que os autores latino-americanos as indicações de primeira escolha da ECT. Os casos especiais, como gestantes e lactentes, são 
melhor abordados no Capítulo $\mathrm{V}$, juntamente com a avaliação pré-ECT, que deve ser realizada cautelosamente, levando-se em consideração o doente, e não a doença, como também as medicações em uso, psicotrópicas ou não, e o ambiente onde serão aplicadas as sessões de ECT.

No Capítulo VI, o Professor de Anestesiologia Dr. Irimar Posso ressalta a necessidade da avaliação pré- e pós-anestésica do paciente, a obtenção do termo de consentimento informado e a complexa área das interações medicamentosas.

No sétimo capítulo são discutidos os efeitos adversos da ECT, os quais se configuram, entre os ignorantes no assunto e antipsiquiatras, como os argumentos mais medíocres contra a utilização desta eficiente técnica biológica.

No oitavo capítulo, é discutido o curso do tratamento, que, realmente, é uma das decisões mais difíceis do psiquiatra e de sua equipe multidisciplinar. Cada serviço terá o seu próprio protocolo, porém o objetivo comum a todos deverá ser sempre o de melhorar a qualidade de vida dos pacientes.

No Capítulo IX, as enfermeiras Elizabeth Jóia, lara Bellegarde e Maguida Stefanelli abordam o papel da equipe de enfermagem psiquiátrica no serviço de ECT, denotando a importância primordial do trabalho do psiquiatra em uma equipe multidisciplinar.

Sobre as considerações éticas da ECT, no Capítulo X, o Prof. Rigonatti e o Psicólogo Antônio Serafim destacam os conceitos de autonomia e competência; e, por que não acrescentar, habilitação. Há de se ter cursos de especialização em ECT nos estados brasileiros.

No penúltimo capítulo, os organizadores e mais os psiquiatras Marco Antonio Marcolin e Demétrio Rumi, os psicólogos Paulo Boggio e Martin Myczkowski, o Doutor em Ciências Felipe Fregni e os médicos residentes de psiquiatria do Instituto de Psiquiatria do Hospital das Clínicas da Faculdade de Medicina da Universidade de São Paulo Carlos Mansur, Carolina Santos e José Gallucci Neto discutem um tema ainda pouco conhecido, que é a estimulação magnética transcraniana (EMT), que pode ser utilizada na neurologia clínica e experimental, como também na psiquiatria, "em vários transtornos, como o transtorno obsessivo-compulsivo, o transtorno do estresse pós-traumático, o transtorno de Tourette e até na esquizofrenia. Porém, a maior parte das pesquisas clínicas se concentra no tratamento dos transtornos depressivos, tanto como tratamento único, como na potencialização dos antidepressivos. A sua eficácia é semelhante, no tratamento de pacientes com depressão maior, às demais terapêuticas, com vantagens de ter início de ação mais rápido e ótima tolerabilidade, por ser praticamente isenta de efeitos colaterais".

No último capítulo, os psicólogos Cristina de Oliveira e Emerson de Oliveira, a musicoterapeuta Ana Cascarani e a psiquiatra Rita Ferreira discorrem sobre tratamentos complementares e de suma importância: arteterapia e musicoterapia. A primeira é "uma modalidade de psicoterapia cujo ateliê pode ser montado na sala de espera do local de aplicação da ECT". Já "a musicoterapia faz parte do grupo das terapias expressivas. O musicoterapeuta pode assistir o cliente antes, durante ou depois da ECT".

No final do livro, são apresentadas, como anexo, as "Resoluções do Conselho Federal de Medicina sobre a Prática da Eletroconvulsoterapia (1640/02) e da Anestesia (1363/93), que vêm facilitar e uniformizar a realização dessa terapêutica em todo o Brasil, assim como auxiliar os psiquiatras a informarem a população leiga sobre este procedimento".

Concluindo, o livro Eletroconvulsoterapia vem brindar a literatura médica brasileira com informações de extrema relevância técnicocientífica e social.

Title: Book review: Eletroconvulsoterapia, by Sérgio Paulo Rigonatti, Moacyr Alexandro Rosa, and Marina Odebrecht Rosa (orgs.)

Título: Reseña del libro Eletroconvulsoterapia, de Sérgio Paulo Rigonatti, Moacyr Alexandro Rosa y Marina Odebrecht Rosa (orgs.)

Copyright (C) Revista de Psiquiatria do Rio Grande do Sul - SPRS 